\title{
Hasanuddin Economics and Business Review: Foreword for the Inaugural Journal Volume
}

\author{
Julia Connell ${ }^{1}$, Abdullah Sanusi ${ }^{2}$ \\ ${ }^{1}$ Visiting Professor, University of Technology, Sydney, Australia \\ ${ }^{2}$ Faculty of Economics and Business, Hasanuddin University
}

\section{The Journal}

We are pleased to write the foreword to the inaugural Journal Volume of the Hasanuddin Economics and Business Review (HEBR). The HEBR is an initiative of the Faculty of Economics and Business, University of Hasanuddin. There will be three volumes published per year covering a range of topics from the key fields of: business; economics and management.

The (HEBR) is an international, double-blind, peer-reviewed, openaccess journal with the goal of providing an academic platform for professionals and researchers to contribute innovative work in the field. It will include original and full-length articles that reflect the latest research and developments in both theoretical and practical aspects of economics, business and management and will be published in both print and online versions (the latter is free access and downloadable).

\section{Another Journal?}

Your first thought when you heard about a new journaI is 'dowe need another business journal'? Although time will tell for this new initiative, the HEBR does provide an outlet for a range of scholars to share their research and showcase their findings - largely emanating from Indonesia - a country much of the rest of the world has a fascination with, and needs to know more about.

As a mid-developed country and an ASEAN member, Indonesia is a country in transition. Research and researchers are needed to analyse, track and report on the transition policies, processes and outcomes both for the Indonesian population and the rest of the world. As the largest economy in Southeast Asia and the fourth-most-populous country in the world, Indonesia has substantial economic and political influence in the Asia-Pacific region. As such, it has the potential to make important

*Corresponding Author: Julia Connell, Julia.Connell@uts.edu.au ISSN: 2549-3221 (Print) 2549-323X (Online) DOI: http://doi.org/10.26487/hebr.v111.1238 
contributions through academic research and the dissemination of knowledge emerging from Indonesian universities (Tilley and Pellini, 2016).

Over recent years Indonesia and Indonesian researchers have increased academic publication outputs as part of the higher education reform initiated by the government (Hill and Wie, 2012). The initiative was intended to increase publication numbers by providing financial incetives for the researchers. However, there is still much room for improvement. The number of publications by Indonesian academics in ASEAN is well behind those of academics based in Malaysia, Singapore and Thailand. Consequently, this new journal can assist the process of showcasing the work of Indonesian scholars in the quest to transition. This is also important as it has been proposed that, increasing publications from Indonesia may assist the production of high-value goods for export, such as chemicals, electronics and bio-medical manufacturing (Tilley and Pellini, 2016).

\section{A Look Inside HEBR}

The inaugural volume of HEBR comprises eight articles which cover a broad spectrum of topics. These range from topics such as tax and accounting, to topics such as innovation, motivation and temporary migration. The approaches taken include an equally broad range of research methods from empirical studies to conceptual and policy articles. The next section provides a brief overview of the papers as an introduction to the volume.

We hope you find the articles interesting and useful to read and that you may even consider contributing an article yourself in the near future.

Several articles are included in the business and management field. The first paper Macroeconomic Energy Efficiency Portfolio Model of Indonesia raises the issue of the decreasing trends in Indonesia's energy efficiency. In the absence of initiatives by the government and Indonesia's citizens to improve energy efficiency, it is projected that it will decline gradually in the next 25 years by around $45.51 \%$. This study attempts to address the policy problems associated with this by providing policy recommendations based on in-depth analysis and evaluation of the policy alternatives.

Examining Temporary Migration as a Solution to the Lean Season represents collaboration between multiple authors representing Yale School of Management and UNHAS students. To examine potential migration, the researchers interviewed farmers of varying degrees of wealth and small business owners who employed migrants to gain insights into incentives that may encourage workers to move to cities for work.

Second, the article entitled "Tax Compliance: An Experimental Approach" examines the tax selfassessment system in Indonesia. As pointed out, the main duty of the tax office is to ensure that taxes calculated and paid by the taxpayers are in accordance with the relevant tax rules. The study examines income tax returns to determine the accuracy of the information provided, using an experimental approach. The findings reveal that research participants reported less income than they should and secondly, that audit and penalty rates were the two most important factors influencing the amount of income reported by the research participants.

The next paper examines the "Effects of accounting information on excess return using Fama and French threefactor model in order to examine capital market reaction due to dividend announcement". The paper discusses 
the effects of accounting information on the excess return of shari'ah stocks and conventional stocks using the Fama and French Three Factor Model, as well as the reaction of the capital markets as a result of the dividend announcement. The results and data analysis yielded 8 stock portfolios leading to the conclusion that the AER variable movements had an immediate reaction to the movement as explained in the article.

The next paper concerns "Accountability in the Internet Era: a Lesson from Local Governments in Indonesia". As the author points out, Indonesia is one of the countries with the highest internet user growth, and local governments in Indonesia use their official website to report the government's activities as a form of accountability to society. Based on content analysis of government reports, this study analysed the factors that affect the level of internet accountability reports in relation to local government websites.

The next article concerns Performance Evaluation and Organization's Culture Impacts on Job Satisfaction and Employees' Performance. Using a survey tool the authors analyse results from employees working in a bank based in Jember, producing a range of research results and practical recommendations to address their findings.

Turning to the topic of innovation and competitiveness next, the article titled 'The Impact of Innovation Strategy toward Business Competitiveness of Manufacturing Industry' examines the effect of administrative innovation on business competitiveness, technical innovations on business competitiveness, process innovation on business competitiveness, and product innovation on business competitiveness. Although it was found that all types of innovation had an impact on business competitiveness, it was concluded that process innovation had more influence on improving business competitiveness compared to the other innovation strategies.

\section{Reference:}

Hill, H., \& Wie, T. K. (2012). Indonesian universities in transition: catching up and opening up. Bulletin of Indonesian Economic Studies, 48(2), 229-251.

Tilley, H., and Pellini, A. (2016). Indonesia's knowledge sector is catching up, but a large gap persists, The Conversation. https://theconversation.com/ indonesias-knowledge-sectoris-catching-up-but-a-large-gappersists-67937 accessed 1/8/107 